\title{
Sensibility of Children of Different Age Groups to Alarm Intervention for Enuresis
}

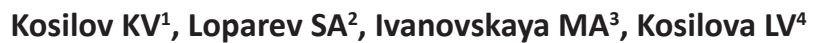

\begin{abstract}
Introduction: Prevalence of primary monosymptomatic night enuresis (PMNE) is high. Age, gender and race of patients, as well as diagnostics criteria used by the researchers, have an impact on the data on enuresis prevalence, and alarm intervention has been used for enuresis treatment for several decades The purpose of this study is to try to find out the difference in efficiency of the Alarm intervention for children of different age for improving recommendations on usage of alarm systems. Materials and Methods: Sampling consisted of 399 persons: 238 males and 161 females suffering PMNE. A method of random numbers was used for group randomization. Persons of both genders at the age of 7 to 15 years old having at least two episodes of nocturnal enuresis per week were included into the treatment group. Then they were distributed into three subgroups where questionnaires were filled, uro-flowmetry and investigations were done Treatment control was carried out with the help of bladder diaries where episodes of nocturnal, spontaneous awakenings in case of desire to urinate and dry nights were registered. Alarm intervention was conducted by standard method with the use of device Wet Stop/ BYE-WET by PALCO LABS, Inc (USA). Results: Initial data showed that children of junior and average age subgroups show optimal response to conducted therapy. However, the results of 10-12-yearold children proved to be stable, the result of 7-9-year-old children was significantly worse in two months after the end of treatment. Conclusion: Alarm intervention has the best direct and long-term effect on 10-12-year old children.
\end{abstract}

Key words: Enuresis, Alarm intervention, Adolescent

\section{Introduction}

revalence of primary monosymptomatic night enuresis (PMNE) is high all over the world. According to various estimations, it varies from 4.7 to $12 \%$ or even more. Age, gender and race of patients, as well as diagnostics criteria used by the researchers, have an impact on the data on enuresis prevalence ${ }^{1,2,3,4,5}$. In 2012 International Children's Continence Society (ICCS) and National Clinical Guideline Centre, UK (NCGC) announced the rules and guidelines specifying several factors that can act as releaser of enuresis. They include change in antidiuretic hormone level, disturbance of sleep and
'Kirill Vladimirovich Kosilov, MD, PhD, Professor of Department of Social Sciences, School of Humanities, Far Eastern Federal University, Vladivostok, Primorsky region, Russian Federation, ${ }^{2}$ Sergay Alexandrovich Loparev, MD, urologist Department of Urology, City polyclinic No 3, Vladivostok, RF, ${ }^{3}$ Marina Anatolievna Ivanovskaya, MD, PhD, Associate Professor, Department of Law, Far Eastern Fisheries University, Vladivostok, $\mathrm{RF}$, ${ }^{4}$ Liliya Viktorovna Kosilova, MD, doctor in the department of functional diagnostics, Med. association No 2 of Vladivostok-sity, Vladivostok, RF. This study was done at the Far Eastern Federal University, School of Humanities, Ajax 10, corp. F, office 733, Vladivostok, Primorsky region, Russian Federation, Tel./fax 7-(4232) 457-693, Website: www.dvfu.ru.

Address for correspondence:

KV Kosilov, MD, PhD

Address: Ajax 10, corp.F, office 733,

Vladivostok, Primorsky region, Russian Federation, RUVVO

E-mail: address: oton2000@mail.ru

Tel No: 7-914-717-3915; 7-423-231-2169

\section{How to cite}

Kosilov KV, Loparev SA, Ivanovskaya MA, Kosilova LV. Sensibility of Children of Different Age Groups to Alarm Intervention for Enuresis. J Nepal Paediatr Soc 2015;35(1):49-56.

doi: http://dx.doi.org/10.3126/jnps.v35i1.11261

This work is licensed under a Creative Commons Attribution 3.0 License.

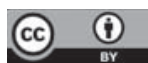

sleep-wake cycle, delayed formation of nerve reflex mechanisms of awakening skill and some others ${ }^{6,7}$. 
Therapeutic procedures for PMNE are also stipulated in ICCS rules. They point out to the use of the Alarm intervention and synthetic analog of antidiuretic hormone as first-line therapy methods $s^{8,9}$.

Alarm intervention has been used for enuresis treatment for several decades ${ }^{10,11,12}$. However, the problem of effectiveness of such therapy in age aspect appears to be insufficiently studied ${ }^{13,14,15,16}$. Meanwhile, it is known that perception of extrinsic stimulates, reactions of involuntary nervous system, resistance of unconditioned nervous reflexes can be quite different among children of various age and teenagers ${ }^{17,18,19}$. Hence, the purpose of this study is to try to find out the difference in efficiency of the Alarm intervention for children of different age for improving recommendations on usage of alarm systems.

\section{Material and Methods}

Sampling consisted of 399 persons: 238 males and 161 females suffering PMNE. Method of random numbers was used for group randomization. Sample size was calculated, using the formula for comparing two mean values and searching for correlations, with refer to the percentage of response and monitoring losses: $n=[A+B]^{2 *} 2 * S^{2} / D I F F 2$, where $n$ is a sample size for each group, SD is standard deviation for primary outcome variable, DIFF is clinically significant effect, A is significance level that is taken as $5 \%$ and $B$ is capacity that is taken at $80 \%$ in this case.

A method of random numbers was used for group randomization. Persons of both genders at the age of 7 - 15 years old having at least two episodes of nocturnal enuresis per week were included into the treatment group. Then they were distributed into three age subgroups: $A$ (7-9 years old; $n=142), B(10-12$ years old; $n=130), C(13-15$ years old, $n=127)$. Persons with any chronic conditions of visceral organs in the exacerbation phase, symptoms of detrusor dysfunction, changed level of antidiuretic hormone and ear disorders were excluded from the group.

In the beginning of examination all the patients, their parents or trustees filled in questionnaire OAB-q $\mathrm{SF}^{20,21}$, while children and teenagers had uroflowmetry tests as well as laboratory tests, including tests for inflammation and determination of antidiuretic hormone level. Treatment control was carried out with the help of bladder diaries where episodes of nocturnal, spontaneous awakenings in case of desire to urinate, dry nights were registered ${ }^{22}$. Examination, treatment and observation scheme are shown in Fig. 1. Study checkpoints 1 and 2 are state of enuresis markers right after treatment and within two months after its end.

Alarm intervention was conducted by standard method with the use of device Wet Stop/ BYE-WET by PALCO LABS, Inc (USA). The Protocol of this randomized controlled study was performed in accordance with Good Clinical Practice (GCP), the Declaration of Helsinki and ICCS.

Initial data were collected by application software Excel from standard Microsoft-XP package and analyzed by JMP SAS Statistical Discovery 8.0.2 (SAS Institute, Cary, NC, USA). Wilcoxon criterion was used for comparison of the results in each group. One-way analysis of variance (ANOVAs) with Tukey and Kramer criterion was used for comparison of the effects in three age subgroups, processes contingency was studied, using Spearman criterion.

Ethics committee approval was received for this study from the ethics committee of the Far Eastern Federal University on February 19, 2013.

\section{Results}

As result of processing questionnaire $O A B-q$ data collected in the beginning of study it was found out that median values of score for patients of the Groups A, B and C were 3.6 (1.1), 2.1 (1.5) and C - 3.3 (1.2) respectively.

The result of uroflowmetry data processing was as followed. Average velocity of urination $\left(Q_{\text {mid }}\right)$ for the Group A was 15.1 (3.7) ml/s., for the Group B - 14.5 (4.9) $\mathrm{ml} / \mathrm{s}$., and for the Group C - 16.1 (3.9) ml/s. Maximum volume velocity of urination $\left(Q_{\max }\right)$ for the Group $A$ comprised 18.5 (4.5) ml/s., for the Group B - 20.7 (6.1) $\mathrm{ml} / \mathrm{s}$., for the Group C - 20.9 (4.8) ml/s. Average volume velocity of urination (V): Group A - 189.4 (32.0) ml, Group B - 209.4 (42.7) ml, Group C - 259.1 (41.7) ml. Average time of achieving maximum urination velocity $\left(Q_{\text {mid }}\right)$ was within normal limits for all age groups.

Average value of antidiuretic hormone was 4.2 (1.1) nanogram/liter, and it corresponded to the standard values at certain level of osmolarity for each patient. Blood and urine tests did not reveal the signs of inflammation process; the markers of helminthes infection were not detected.

Table 1 shows the changes in frequency of enuresis episodes, spontaneous awakenings and number of dry nights in the beginning of study right after the end of its active phase and in two months after the end of alarm systems usage. 
Significant decrease in the number of dry nights after treatment was reported in junior and average age groups, yet in two months after the end of the Alarm intervention only the variations from initial values of patients of older group proved to be significant. Comparison of final values of this parameter between the groups allows to conform the significance of differences between the Group $B$ on the one hand and Groups $A$ and $C$ - on the other hand ( $p \leq 0.05$ in both cases).

Right after the end of treatment, the reduction in number of episodes of enuresis was reported in junior and average age groups, while the final values proved to be significantly different from initial ones in Groups B (4.6 (0.9) $\rightarrow 2.6(0.6), p \leq 0.05)$ and C ( $4.8(0.8) \rightarrow 2.9$ $(0.6), p \leq 0.05)$. Significant difference between initial and final values of parameter "spontaneous awakening episodes" was reported for the patients of junior and average age groups. Final values of the parameter in the Group B are significantly higher than those in other groups ( $p \leq 0.05)$. Final numbers episodes of enuresis in Groups B and C are not significantly different among each other and are significantly lower than in junior group.

Figures 2 and 3 represent monthly dynamics of average number of dry nights and enuresis episodes during the experiment.

Figures 2 and 3, show monthly changes in average numbers of dry nights and enuresis episodes during the experiment.

The curves reflecting changes in the number of cases of nocturnal urination are almost synchronous for Groups B and C ( $r=0.83, p \leq 0.01)$ and moderately conjugate between the Group $A$ on the one hand and Groups B and C - on the other hand (A-B: $r=0.49$, $p \leq 0.05$; $A-C: r=0.57, p \leq 0.05)$. Correlation between the curves demonstrating the changes in the number of episodes of nocturnal urination $\mathrm{i}$ was also quite high (B-C: $r=0.90 \mathrm{p} \leq 0.01$; A-C: $r=0.59 p \leq 0.05$; A-B: $r=0.64$ $p \leq 0.05)$.
In junior age group the average number of alarm system actuations prior to the appearance of the first spontaneous awakening in case of desire to urinate was 6.8 (1.9), while the same parameter for the children of average and older age groups proved to be equal to 8.7 (4.1) and 12.2 (5.8) respectively.

Fig. 4 shows the change in the number of patients (in percentage points) who suffered from PMNE during the whole monitoring period. As graphs suggest, the most positive result of Alarm-therapy has been reported in the Group B. In this group, not only was the percentage of children who suffer from PMNE right after the treatment the lowest one, but also the result turned out to be the most stable one among all three groups. When carrying out study in 2 months after the end of active phase of the experiment, the percentage of children who suffered from enuresis symptoms did not significantly change $(25.2 \% \rightarrow 28.5 \%, p \geq 0.5)$. Decent initial result was achieved in the group of younger children too (A). The percentage of patients who turned out to be resistant to the Alarm-therapy was $31.1 \%$, yet as early as in two months their proportion reached $57.4 \%$, i.e. nocturnal urination episodes of more than twice a week were reported for almost one child in two. Finally, in the group of older children, therapy course turned to be the least effective. The percentage of children who suffered PMNE right after its end and in two months after were $48.5 \%$ and $51.3 \%$ respectively.

Thus, the effectiveness of the Alarm-therapy in the group of teenagers of 12 to 14 has turned out to be the highest, with its result being the most stable one among all the groups to be compared.

During the experiment, 28 persons (7.0\%) refused to participate in it. Among them, from group A - 13 people (3.2 \%) belonged to the Group A, 7 people (1.7\%) belonged to the Group B and 8 people $(2.0$ $\%)$ belonged to the Group A. The reasons of refusal were- acute inflammatory diseases (10 cases (2.5\%), negative psycho-emotional response to Alarm-therapy ( 7 cases $(1.7 \%)$, and other reasons that were not related to the treatment 11 cases $(2.7 \%)$. 


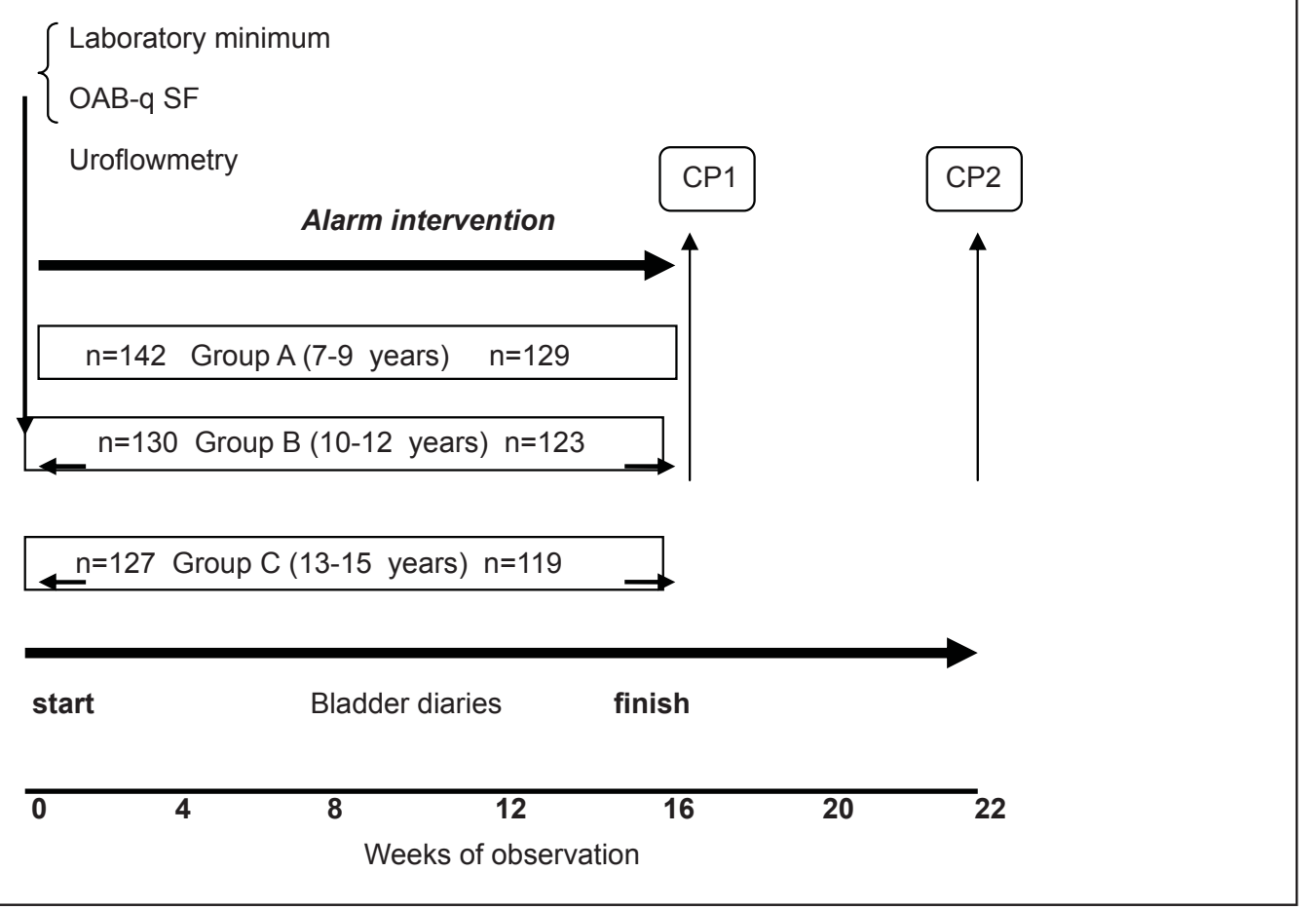

Fig 1: Scheme of examination and treatment of children and adolescents with PMNE $(n=399)$

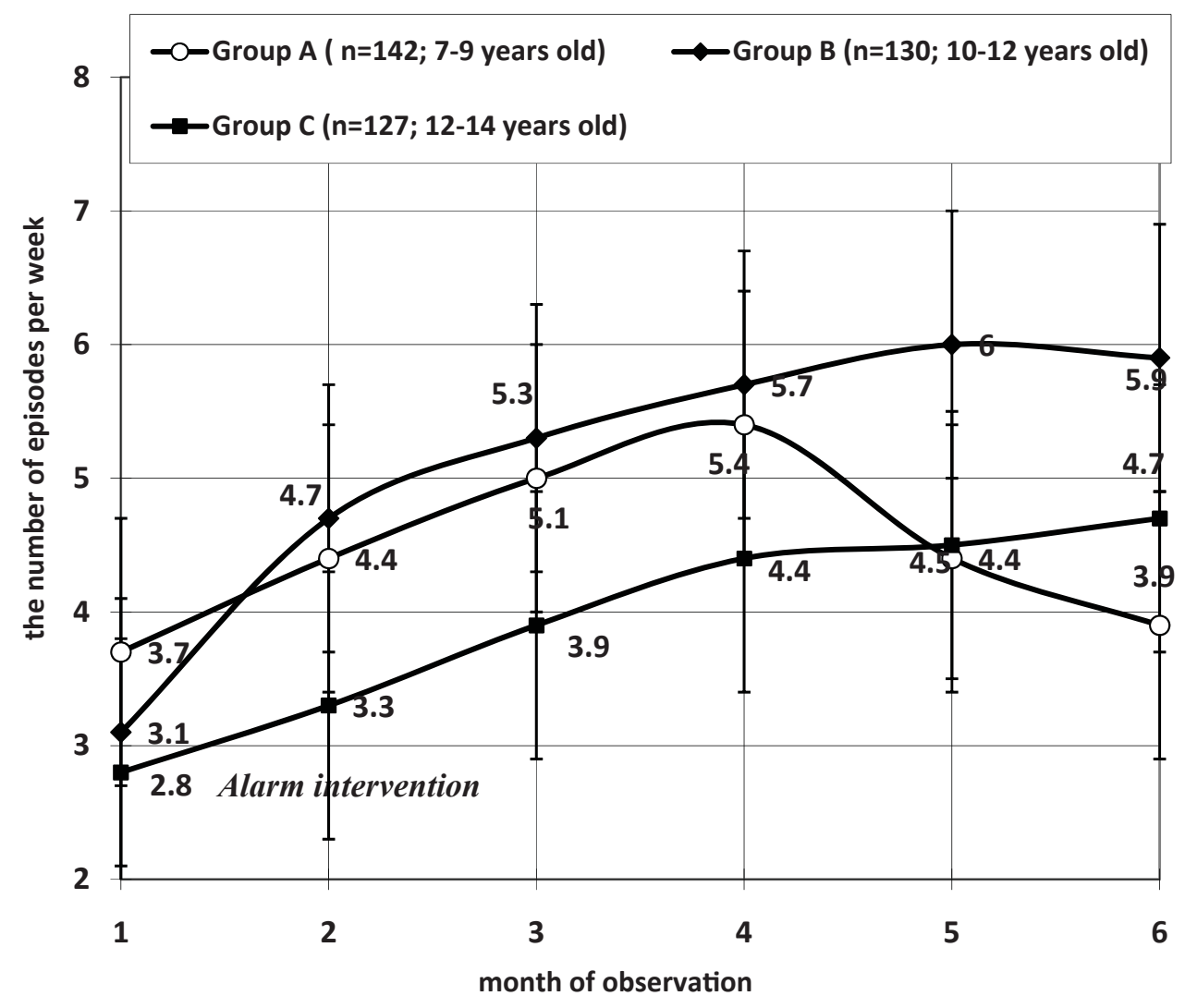

Fig 2: The change in frequency of episodes of "dry" nights (per week) with alarm therapy in different age groups ( $\mathrm{n}=$ 399) 


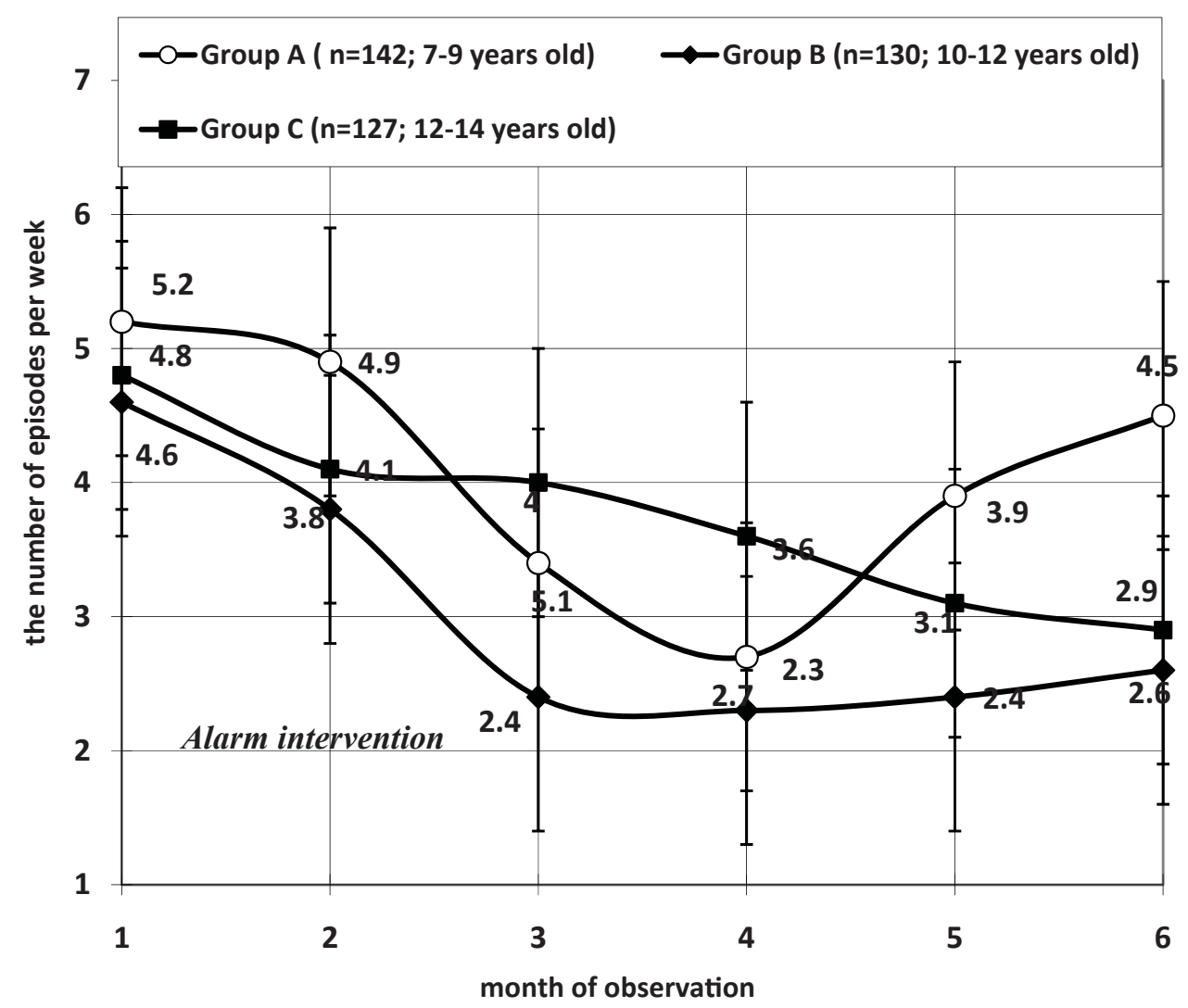

Fig 3: The change in frequency of episodes of enuresis (per week) with alarm therapy in different age groups $(n=399)$

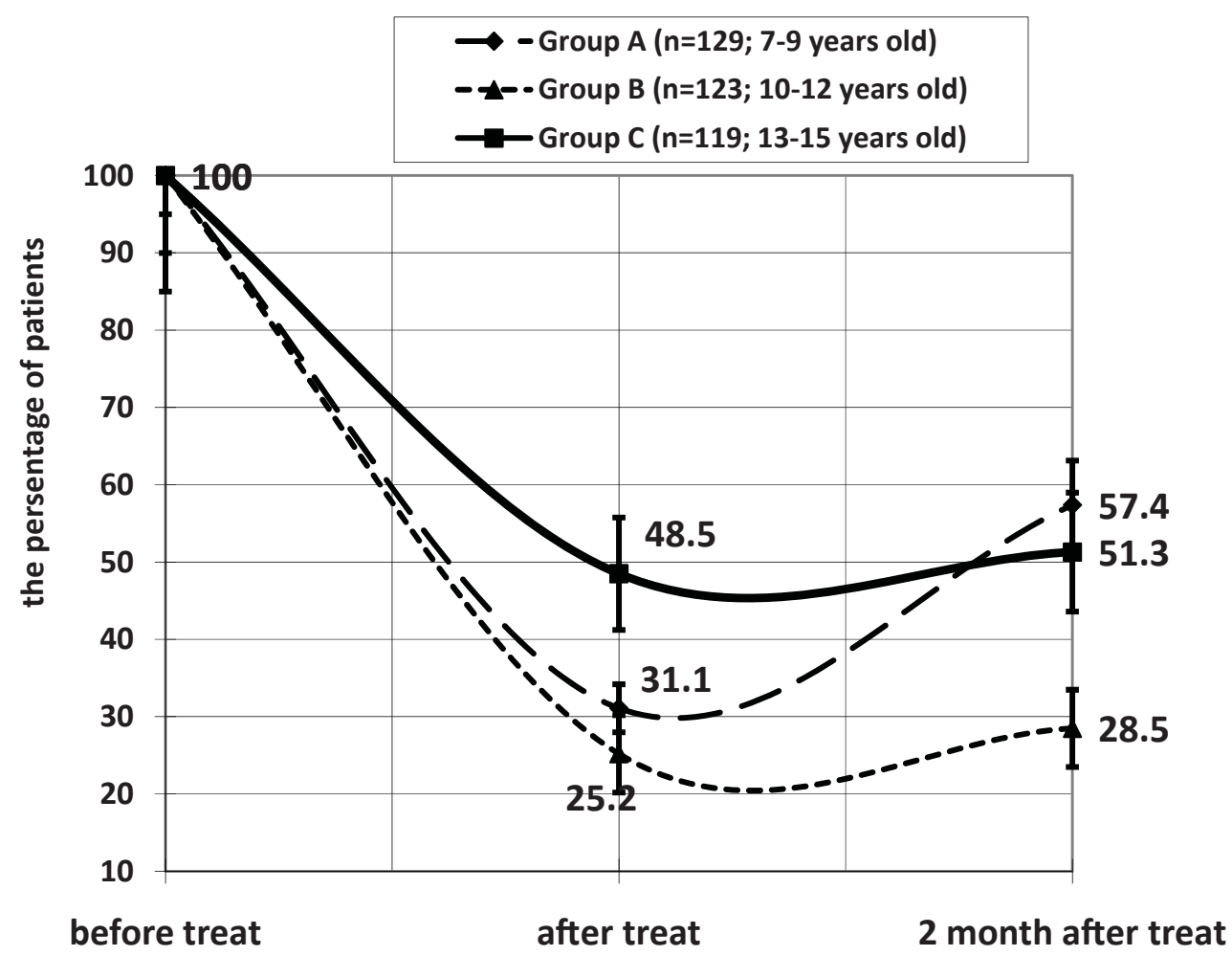

Fig 4: The percentage of patients with PMNE before treatment, immediately after treatment and two months after the end of treatment. 
Table 1: Dynamics of performance criteria of Alarm intervention in groups A ( $n=142 ; 7-9$ years), B ( $n=130 ; 10-11$ years) and $C(n=127 ; 12-15$ years)

\begin{tabular}{|c|c|c|c|c|c|c|c|c|c|}
\hline & \multicolumn{3}{|c|}{$\begin{array}{l}\text { The average number of } \\
\text { "dry" nights (per week) }\end{array}$} & \multicolumn{3}{|c|}{$\begin{array}{c}\text { The average number of episodes } \\
\text { of enuresis (per week) }\end{array}$} & \multicolumn{3}{|c|}{$\begin{array}{c}\text { The average number of } \\
\text { self-awakenings (per week) }\end{array}$} \\
\hline & $\begin{array}{l}\text { Prior to } \\
\text { treat }\end{array}$ & $\begin{array}{l}\text { After } \\
\text { treat }\end{array}$ & $\begin{array}{l}\text { Two } \\
\text { month } \\
\text { after }\end{array}$ & $\begin{array}{l}\text { Prior to } \\
\text { treat }\end{array}$ & $\begin{array}{l}\text { After } \\
\text { treat }\end{array}$ & $\begin{array}{l}\text { Two } \\
\text { month } \\
\text { after }\end{array}$ & $\begin{array}{l}\text { Prior to } \\
\text { treat }\end{array}$ & $\begin{array}{l}\text { After } \\
\text { treat }\end{array}$ & $\begin{array}{l}\text { Two } \\
\text { month } \\
\text { after }\end{array}$ \\
\hline $\begin{array}{c}\text { Group A } \\
\text { (7-9 } \\
\text { years) }\end{array}$ & $3.7(0.7)$ & $5.4(0.7)^{*}$ & $3.9(0.6)$ & $5.2(1.1)$ & $2.7(0.8)^{*}$ & $4.5(1.2)$ & $0.7(1.3)$ & $2.9(0.5)^{*}$ & $1.4(1.5)$ \\
\hline $\begin{array}{c}\text { Group B } \\
(10-12 \\
\text { years) }\end{array}$ & $3.1(0.9)$ & $5.7(0.7)^{*}$ & $5.9(1.1)^{*}$ & $4.6(0.9)$ & $2.3(0.7)^{*}$ & $2.6(0.6)^{*}$ & $1.3(0.6)$ & $\begin{array}{c}4.4 \\
(1.0)^{* *}\end{array}$ & $3.1(0.8)^{*}$ \\
\hline $\begin{array}{c}\text { Group C } \\
\text { (13-15 } \\
\text { years) }\end{array}$ & $2.8(0.9)$ & $4.4(1.2)$ & $4.7(1.4)$ & $4.8(0.8)$ & $3.6(1.5)$ & $2.9(0.6)^{*}$ & $2.3(1.2)$ & $3.7(1.1)$ & $3.9(1.3)$ \\
\hline
\end{tabular}

In parentheses is the standard deviation (SD). The significance of differences $*_{-} p<0.05 ; *_{-}^{*} p<0.01$. The table shows the significance of the differences between the results before treatment vs the results immediately after treatment and 1 month after treatment.

\section{Discussion}

In our opinion, the obtained results allow to assume that sensibility of non-adults to the therapy with the use of alarm systems essentially changes with age.

Initial data allow concluding that children of junior and average age subgroups show optimal response to conducted therapy. However, if the result of 10-12-year-old children proved to be stable, the result of 7-9-year-old children was significantly worse within 2 months after the end of treatment.

In our opinion, one of the explanations of these results could be features of growth and development of central regions autonomic nerve system in this age among children who suffer from PMNE. The responses of such autonomic system to irritators probably turn weaker among older children who suffer from enuresis, comparing with younger ones. Central and peripheral structures of the autonomic system loose lability (or course, relatively), while development and fixation of conditioned reflex links are carried out less effectively ${ }^{23,24,25,26}$. It may be one of the reasons for weaker response of the patients of senior age group to suggested therapy algorithm.

In this regard, the study that has been recently carried out by Lei D et al (2012) to study the changes in spontaneous activity and microstructure of various brain regions among children and teenagers who suffer from PMNE 27,28, using magnetic resonance imaging (MRI), seem to be interesting. Substantial differences in basic rhythms of left lower frontal gyrus, medial frontal gyrus and some other brain regions related to data processing were detected among children who suffer from PMNE. Microstructural failures were detected in thalamus, medial frontal gyrus and other regions related to the regulation of urine output. The authors of this study argue that detected anomalies may have an impact on the transmission of neural signals that regulate bladder function and on the processes related to awakening. The authors also assume that delay in normal development and differentiation of studied fields may cause the emergence of PMNE. Esposito M et al $(2013)^{29}$ also point out to the necessity of taking into account the delay in development of central regions of autonomic nerve system and immaturity of nerve and reflex mechanisms when establishing diagnosis and choosing therapy for children who suffer from PMNE.

It is probably microstructural failures and, subsequently, functional immaturity of autonomic nerve system that are of the reasons for different response of children of various age to the standard algorithm of the Alarm-therapy. In this view, relative instability and easy loss of newly acquired skill exactly among children of younger age seem to be understandable too.

In their review of enuresis therapy methods, based on the results of eight recent studies, Perrin $\mathrm{N}$ et al (2013) report that prolonged use of the Alarm intervention achieves better results than taking desmopressin ${ }^{30}$. Ahmed AF et al. (2013) also point out to better result achieved by using signal systems and 
its higher survival, compared to desmopressin, which can be interpreted as important indirect evidence of delay of autonomic nerve system development among children of younger age ${ }^{31}$.

Thus, relatively high functional elasticity, easiness of development and fixation of conventional-reflex connections are typical for 7-12-year-old children. However, the the other side of this process is relative instability and easy loss of newly acquired skills ${ }^{32-33}$. In our experiment, quick formation of conditioned reflex of awakening in case of desire to urinate resulted with their equally quick loss among younger children lost it quickly after the end of alarm systems use, while older patients had more stable effect.

\section{Conclusion}

Children of the age group 7-9 and 10-12-year-old were most sensitive to the alarm therapy of PMNE. However, in case of younger children, the effect of increase in the number of dry nights, acquiring skill of awakening in case of desire to urinate and reduction in the number of episodes of incontinence in sleep significantly declined within two months. The signs of alarm intervention of enuresis among 13-15-year-old children were less efficient, but the result was more stable. The results thus obtained, by all means, cannot be considered as sufficient and require further studies however alarm intervention had the best direct and long-term effect on 10-12-year old children.

\section{Acknowledgements: Nil \\ Funding: Nil \\ Conflict of Interest: None \\ Permission from IRB: Yes}

\section{References}

1. Hashem M, Morteza A, Mohammad K. Prevalence of nocturnal enuresis in school aged children: the role of personal and parents related socioeconomic and educational factors. Iran J Pediatr 2013 Feb;23(1):59-64.

2. Kajiwara $M$, Inoue K, Mutaguchi K, Usui T. The prevalence of overactive bladder and nocturnal enuresis in Japanese early adolescents: a questionnaire survey. Hinyokika Kiyo 2006;52(2):107-11.

3. Kiddoo DA. Nocturnal enuresis. CMAJ 2012 May 15;184(8):908-11.

4. Lottmann HB, Alova I. Primary monosymptomatic nocturnal enuresis in children and adolescents. Int J Clin Pract Suppl 2007;(155):8-16.
5. Baek $\mathrm{M}$, Park $\mathrm{K}$, Lee $\mathrm{H}$ et al. A nationwide epidemiological study of nocturnal enuresis in Korean adolescents and adults: population based cross sectional study. J Korean Med Sci 2013;28(7):1065-70.

6. Vande Walle J, Rittig S, Bauer $S$ et al. Practical consensus guidelines for the management of enuresis. Eur J Pediatr 2012;171(6):971-83.

7. Harari MD. Nocturnal enuresis. J Paediatr Child Health 2013;49(4):264-71.

8. Norfolk S, Wootton J. Nocturnal enuresis in children. Nurs Stand 2012;27(10):49-56; quiz 58.

9. Nocturnal Enuresis: The Management of Bedwetting in Children and Young People. National Clinical Guideline Centre (UK). London: Royal College of Physicians (UK); 2010.

10. S Halliday, S R Meadow, and I Berg. Successful management of daytime enuresis using alarm procedures: a randomly controlled trial. Arch Dis Child 1987;62(2):132-137.

11. H Palmer Electric bell alarm for enuretics. Br Med J 1970;1(5695):567.

12. E Fleming Electronic bed wetting alarm and toilet trainer. Br Med J (Clin Res Ed). 1982; 285(6340):512.

13. O'Flynn N. Nocturnal enuresis in children and young people: NICE clinical guideline. $\mathrm{Br} J \mathrm{Gen}$ Pract 2011;61(586):360-2

14. Glazener CM, Evans JH, Peto RE. Treating nocturnal enuresis in children: review of evidence. $J$ Wound Ostomy Continence Nurs 2004 Jul;31(4):223-34.

15. Ozgür BC, Ozgür S, Doğan V, Orün UA.The efficacy of an enuresis alarm in monosymptomatic nocturnal enuresis. Singapore Med J 2009;50(9):879-80.

16. Butler RJ, Gasson SL.Enuresis alarm treatment. Scand J Urol Nephrol 2005;39(5):349-57.

17. Vanderlei LC, Pastre CM, Freitas Júnior IF et al. Analysis of cardiac autonomic modulation in obese and eutrophic children. Clinics (Sao Paulo) 2010;65(8):789-92.

18. Echeverría JC, Solís LI, Pérez JE et al. The autonomic condition of children with congenital hypothyroidism as indicated by the analysis of heart rate variability. Auton Neurosci 2012;167(1-2):7-11.

19. Torun E, Gursoy E, Guler S. et al.Characteristic features of migraine in schoolchildren and adolescents and its relationship with autonomic nervous system disorders. Neuropediatrics 2013;44(5):252-6. 
20. Arlandis S, Ruiz MA, Errando C. et al. Quality of life in patients with overactive bladder: validation and psychometric properties of the Spanish Overactive Bladder Questionnaire-short Form. Clin Drug Investig 2012;32(8):523-32.

21. McKown S, Abraham L, Coyne $K$ et al. Linguistic validation of the N-QOL (ICIQ), OAB-q (ICIQ), PPBC, OAB-S and ICIQ-MLUTSsex questionnaires in 16 languages. Int J Clin Pract 2010;64(12):1643-52.

22. Kwak KW, Park KH. Clinical inconsistency of lower urinary tract symptoms between questionnaire and bladder diary in children with nocturnal enuresis. J Urol 2008;180(3):1085-9.

23. Luciana M. Adolescent brain development: current themes and future directions. Introduction to the special issue. Brain Cogn 2010;72(1):1-5.

24. Sisk CL, Zehr JL. Pubertal hormones organize the adolescent brain and behavior. Front Neuroendocrinol 2005;26(3-4):163-74.

25. Norman M Wolfish. Enuresis: A maturational lag. Paediatr Child Health 2002;7(8):521-523.

26. Shvarkov SB, Veĭn AM, Kovrov GV, Posokhov SI. The epidemiology of autonomic disorders in Moscow schoolchildren. Zh Nevrol Psikhiatr Im S S Korsakova. 1993;93(6):59-61

27. Lei $\mathrm{D}, \mathrm{Ma} J, \mathrm{Du} \mathrm{X}$ et al.Spontaneous brain activity changes in children with primary monosymptomatic nocturnal enuresis: a restingstate fMRI study. Neurourol Urodyn 2012;31(1):99104.

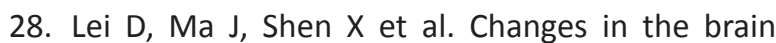
microstructure of children with primary monosymptomatic nocturnal enuresis: a diffusion tensor imaging study. PLoS One 2012;7(2):e31023.

29. Esposito M, Gallai B, Parisi L et al. Visuomotor competencies and primary monosymptomatic nocturnal enuresis in prepubertal aged children. Neuropsychiatr Dis Treat 2013;9:921-6.

30. Perrin N, Sayer L, While A.The efficacy of alarm therapy versus desmopressin therapy in the treatment of primary mono-symptomatic nocturnal enuresis: a systematic review. Prim Health Care Res Dev 2013;19:1-11.

31. Ahmed AF, Amin MM, Ali MM et al. Efficacy of an enuresis alarm, desmopressin, and combination therapy in the treatment of saudi children with primary monosymptomatic nocturnal enuresis. Korean J Urol 2013;54(11):783-90.

32. Bottomley G. Treating nocturnal enuresis in children in primary care. Practitioner 2011;255(1741):23-6, 2-3.

33. Ellington EE, McGuinness TM. Mental health considerations in pediatric enuresis. J Psychosoc Nurs Ment Health Serv 2012;50(4):40-5. 